118

\title{
DISTRIBUZIONE DEI GENOTIPI DI VIRUS C IN UN CAMPIONE DI PAZIENTI NELL'AREA METROPOLITANA DI NAPOLI .
}

Scarallo G., Quartotti A., Marino F., Fasano S., Varelli G.

Istituto Diagnostico Varelli di Napoli

Introduzione. L'epatite di tipo C costituisce attualmente uno dei più importanti problemi di sanità pubblica a livello mondiale; in Italia i portatori cronici di dell'HCV sarebbero più di un milione. Il genoma dell'HCV presenta notevole grado di eterogeneità intrinseca, l'esistenza di molteplici popolazioni virali è un possibile meccanismo attraverso il quale il virus sfugge alla sorveglianza immunitaria. In Italia vi è una netta prevalenza del genotipo $1 \mathrm{~b}$. La caratterizzazione molecolare permette di valutare l'aggressività ed il comportamento clinico dei singoli genotipi insieme alla risposta alla terapia farmacologia.

Metodi. Nell'arco temporale 2003-2005, sono stati tipizzati i genotipi HCV di 123 pazienti, provenienti dall'area metropolitana di Napoli, che dovevano sottoporsi a terapia inteferonica. A tal fine è stato utilizzato il test VERSANT HCV Genotipo (Line Probe Assay - LiPA), basato sull'ibridazione inversa su striscia singola, prodotto da Bayer.

Risultati. Il genotipo $1 \mathrm{~b}$ è risultato essere il più frequente (64\%); il genotipo 1a è stato riscontrato nel $7 \%$ dei soggetti. Il genotipo 2 è stato individuato nel $27 \%$ dei soggetti (2a$22 \%$; $2 \mathrm{a} / 2 \mathrm{c}-5 \%$ ), il 3 (3a) nel $5 \%$, ed infine il 4 (4c) nel $2 \%$. Non è stata osservata una significativa differenza tra i due sessi per quanto riguarda la frequenza d'infezione di un determinato genotipo. L'età media è risultata essere di 53 anni, ma la distribuzione per fascia di età evidenzia un picco tra i 50-70 anni (mediana 61), che rappresenta oltre il 70\% dei soggetti esaminati.

Conclusioni. La popolazione in esame presenta una percentuale di soggetti "anziani" preponderante, ed il genotipo più frequente è risultato essere, come ci si attendeva, di tipo $1 \mathrm{~b}$; i genotipi meno frequenti nell'area italiana, in particolare $3 \mathrm{a}$ e 4C, sono stati identificati sia in soggetti anziani che giovani, senza alcuna prevalenza significativa. 